\title{
NEW SOUTH AMERICAN SARCOPHAGIDAE (DIPTERA)
}

By DAYTD G. HALL, Bureau of Entomology and Plant Quarantine, United States Department of Agriculture, Washington, D. C.

The following species of Sarcophagidae are described in order to make the names available for Mr. L. F. Martorell, of the Puerto Rican Experiment Station at Río Piedras, who collected the specimens.

\section{Sarcophaga camura, new species}

\section{Figure 1}

Male.-Head with front narrow, 0.18 of head width; parafacial and para. frontal silvery pollinose, with a slight yellowish tinge, the former bare; frontal bristles about eight or nine, the rows not widely diverging below, and descending about to the base of the second antennal segment; reclinate fronto-orbital bristles absent; ocellar bristles minute, outer vertical bristles not differentiated; antenna rather yellowish, third segment nearly three times length of second and reaching nearly to vibrissae, which are normal and at oral margin; clypeus long and narrow; epistoma short and hardly narrowed; arista with long plumosity; palpus and proboscis black, both ordinary; bucea short, less than onefifth eye height, and with both black and pale yellowish-brown hairs before the metacephalic suture; back of head with one row of postocular eiliae and with pale hairs below.

Thorax silvery pollinose, with the normal three to five black stripes; propleura bare; anterior acrostichal bristles absent; anterior dorsocentral bristles two; humeral bristles two; posterior dorsocentral bristles three; sternopleural bristles two; prescutellar bristles present but reduced; laterally and below with long, yellowish-brown hairs; seutellum with three marginal bristles and without preapical or apical bristles.

Abilomen tessellated and with three shifting black stripes; median marginal bristles on both second and third visible segments; fourth visible segment with a marginal row of about 12 bristles; laterally and below with long yellowishbrown hair.

Hypopygium of normal size; first segment black and heavily grayish pollinose; second segment smaller than first, black, with abundant, long, curling, black hairs; genital features as illustrated.

Wing hyaline; costal spine absent; third costal section about as long as fifth; first and fifth veins bare; third vein with some basal setulae; basicosta yellow.

Legs black; fore and middle femora distally and below with some long yellowish-brown hairs; middle tibia with one anterodorsal bristle and some villosity; hind femur and tibia with long villosity. 
Female.-Unknown.

Type locality._- 'La Providencia', Maracay, Venezuela.

Type and paratype.-U. S. National Museum No. 52069.

Remarks.-Described from the type and one male paratype collected November 13, 1932, by Serres and Martorell.

The peculiar elongate yellowish-brown pile or hair on the sternum and venter in this species approaches the condition found in Sarothromyinae. This species runs to Mehria End. in Townsend's keys, 1935, Manual of Myiology, 2, but is not closely related to Sarcophaga nemoralis $\mathrm{Kr}$., the genotype of Mehria, which is European. I describe it in the genus Sarcophaga sens. lat. until additional related material can be studied.

\section{Sarcophaga rimosa, new species}

Figure 2

Male.-Head with front very narrow, only 0.14 of head width; one parafrontal only one-third width of frontal stripe; parafrontal and parafacial bright golden pollinose, the pollinosity becoming thinner toward vertex; facio-orbital bristles present in several rows below, near eye; frontal bristles about 14, the rows widely diverging below and extending to about the middle of the second antennal segment; inner vertical bristles present; vibrissae considerably above oral margin and slightly approximated, bucca about one-fourth eye height, with only black hair before the metacephalic suture; back of head with one and a partial second row of postocular eiliae.

Thorax black, with six yellowish, dorsal, longitudinal stripes, two median, two postsuturally extending over the postalar callus, and two extending over the humeri and notopleurae to the postalar callus; a golden pleural stripe extending across the propleura, metapleura, and pteropleura; anterior acrostichal bristles three; posterior acrostichal bristles three or four; anterior dorsocentral bristles three; posterior dorsocentral bristles four; sternopleural bristles three; scutellum black with golden pollen, except for a median longitudinal stripe, with two marginal bristles, one subapical bristle, and one apical bristle.

Abdomen black, tessellated, with four rows of golden pollinose spots, these spots not extending to the posterior margins of the segments; third segment with median marginal bristles; fourth segment with a marginal row of about 12 brist'es; fifth sternite reddish-orange, the two arms widely diverging and with long, thin hairs along the inner margins.

Hypopygium of normal size; first segment red; second segment globose, smaller than first, red, with long, curling, black hairs. Genital features as illustrated.

Wing hyaline, third eostal section as long as fifth; third vein with several basal setulae.

Legs black; anterior tibia with one posterior bristle at apical third; mid femur with two posterior bristles near apex; mid tibia with one anterodorsal bristle at apical third; hind tibia without long villosity. 
Female.-Unknown.

Type locality._"La Provindencia”, Maracay, Venezuela.

Type.-U. S. National Museum No. 52071.

Remarlis.-This species appears to some extent like species of Orobrachycorna Tus., which differ by having three posterior dorsocentral bristles; also like species of Dexosarcophaga. Tns., which differ by having the hypopygium red and the second segment of the abdomen with median marginal bristles.

\section{Abacantha, new genus}

Male.-Head without parafacio-orbital bristles; frontal bristles about seven, the rows hardly divergent below; one proclinate fronto-orbital bristle and one reclinate fronto-orbital bristle; outer vertical bristle distinct; third antennal segment fully four times as long as second and reaching almost to the vibrissae, which are normal and at the oral margin; bucea short, less than one-fourth eye height.

Thorax without anterior acrostichai bristles; posterior dorso-central bristles two; sternopleural bristles three; prescutellar acrostichal bristles present.

Abdomen with median marginal bristles on the third segment.

Wing hyaline; first vein setulose.

Legs: Mid femur with comb; hind tibia without villosity.

Genotype.-Abacantha zygox, new species.

\section{Abacantha zygox, new species}

Figure 3

Male.-Head with front 0.29 of head width; parafrontals and parafacials golden pollinose; antenna black; palpus and proboscis black, both ordinary; bueca with only black hair before the metacephalic suture; back of head with two rows of postocular ciliae, around the middle and below with but pale hair.

Thorax silvery-gray pollinose, with the normal three to five black stripes; scutellum with three marginal bristles and one apical bristle.

Abdomen tessellated and with three shifting black stripes; fourth segment black to apex and with a marginal row of about 12 bristles. Fifth sternite yellow-orange, the inside margins of the two divergent arms covered with soft yellowish pile.

Hypopygium with the first segment red, darker at base and without the customary row of marginal setae; second segment red, small, retracted. Genital features as illustrated.

Wing without costal spine, third costal segment about as long as fifth; third vein with some basal setulae.

Legs black, mid tibia with one anterodorsal bristle.

Type locality._- "La Providencia”, Maracay, Venezuela.

Type and paratype.-U. S. National Museum No. 52072. 
Remarlis.-Described from the holotype male, collected by Martorell, and one paratype male collected at San Mateo, Costa Rica, by Pablo Schild, dates unknown.

This species appears close to species belonging to Notochaeta Aldrich, having but two posterior dorsocentral bristles. The setulose first vein is suggestive of Micronotochaeta Townsend but the head shape of this genus is different. I have not seen specimens of Anaravinia Tns, but this genus lacks the ctenidium on the mid femur. Catheronychia Tns. is composed of much smaller species, all of which have three posterior dorsocentral bristles.

\section{Tripanurga albicans (Wiedemann)}

\section{Figure 4}

Sarcophaga albicans Wied., 1830, Auss. Zweifl. 2, p. 363. Tripanurga albicans (Wied.), Br. \& Berg. 1891, Zweifl. Kais. Mus. 5, p. 363.

The following description is given to supplement the inadequate descriptions published heretofore.

Male.-Head with front 0.3 of head width; parafrontals and parafacials silvery-gray pollinose, the latter with a row of facio-orbitals below near eye; frontal bristles about six, the rows slightly converging below and reaching to the antennal insertion; proclinate fronto-orbital bristles one; reclinate frontoorbital bristles one; outer vertical bristles present; antenna black, third segment at least three times as long as the second and reaching almost to the vibrissae, which are normal and at the oral margin; aristal plumosity normal; palpus and proboscis black, both ordinary; bucea one-third the eye height and with only black hair before the metacephalic suture; back of head with one defined row of post-ocular ciliae, around the middle and below with some pale hair.

Thorax silvery-gray pollinose and with the normal three to five black stripes; anterior acrostichal bristles absent; anterior dorso-central bristles two; posterior dorso-central bristles four; sternopleural bristles two; prescutellar acrostichal bristles present; scutellum with two marginal bristles and one preapical bristle.

Abdomen tessellated and with three shifting black stripes; median marginal bristles on the third segment only; fourth segment with a marginal row of about 10 bristles. The posterior part of the abdomen is enlarged and deepened for the reception of the large hypopygium.

Hypopygium with the first segment black, dusted with gray pollen and with a marginal row of about 10 setae; second segment smaller, black, with whitish pollen. Genital features as illustrated.

Wing hyaline; third costal segment as long as fifth, third vein with several setu'ae at base; first vein setulose.

Legs black; middle tibia with two anterodorsal bristles. 
Female.-With two proclinate fronto-orbital bristles and the abdomen of normal shape and depth, otherwise as in male except for normal sexual differences.

Remarks.-The type locality of this species is Brazil, and all of the previous material I have seen has been Brazilian. It is therefore interesting that Serres and Martorell collected one male and one female of the species on November 13, 1932, at "La Providencia". Maracay, Venezuela. 


\section{Explanation of Figures}

Fig. 1.-Sarcophaga camura, n. sp., Left lateral view of male terminalia.

Fig. 2.-Sarcophaga rimosa, n. sp., Left lateral view of male ter-. minalia, and rear view of male penis and forceps.

Fig. 3.-Abacantha zygor, n. sp., Left lateral view of male terminalia.

Fig. 4.-Tripanurga albicans (Wied.). A.-Left lateral view of male terminalia, B.-Penis from same view. 


\section{PLATE VIII}

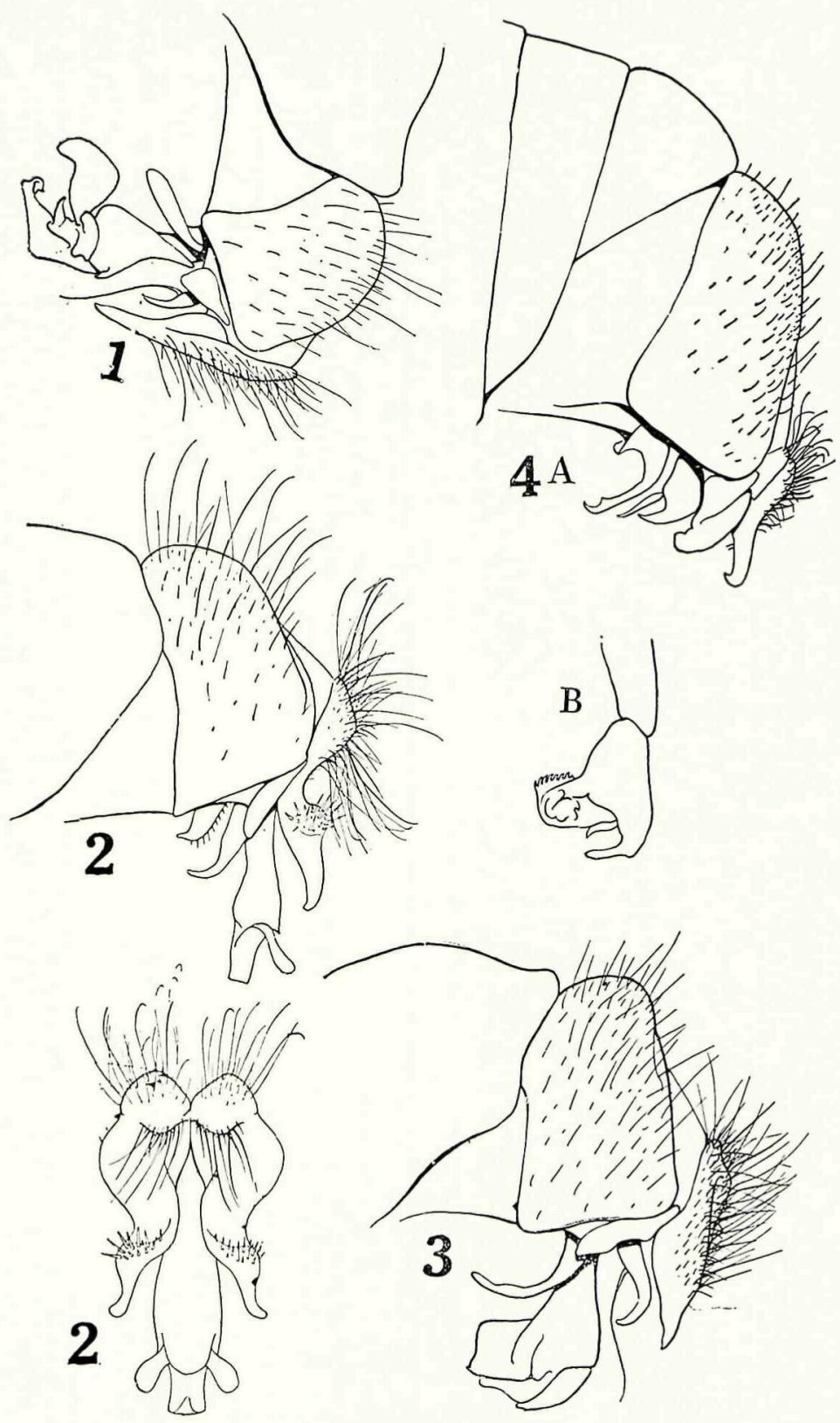

